\title{
IMAGENS EM NARRATIVA: CONTRAPOSIÇÃO CULTURAL E INTERDISCIPLINARIDADE NO ENSINO FUNDAMENTAL
}

\author{
Pictures in narrative: cultural counterpoint \\ and interdisciplinarity in Secondary Education
}

Lucia Maria Paleari ${ }^{1}$

Antonio Carlos Biz ${ }^{2}$

Resumo: Com as transformações pelas quais passa o conhecimento científico na atualidade, a narrativa transformou-se em tema de relevância, quando se pesquisam questões relativas à construção de significado na experiência humana. Investigada como técnica de ensino junto a alunos de $6^{a}$ série de Botucatu, São Paulo, os quais foram confrontados com o ambiente urbano de Salvaterra, Ilha de Marajó, revelou que a força das oposições binárias, previstas teoricamente, estimula a reelaboração de conceitos prévios, revisão e resignificação de valores e de condicionamentos sociais. A narrativa como técnica de ensino propicia aprendizagem efetiva, com o espectador organizando a sequência de imagens apresentada e fazendo emergir significado de acordo com as suas experiências e estrutura cognitiva.

Palavras-chave: Ensino de Ciências. Narrativa. Imagens em narrativa. Técnicas de ensino. Interdisciplinaridade.

Abstract: The current scientific knowledge shift has transformed the narrative into a relevant theme when we search the significance of the human experience. Investigated as a teaching technique among sixth year students from Botucatu City, in São Paulo State, that were confronted by the urban environment of the Salvaterra Village, on Marajó Island, in Brazil, it revealed the strength of the binary oppositions, that are previewed in the conceptual sketch, stimulated the re-elaboration of the previous concepts, and re-signification of both, values and social conditioning. The narrative, used as a teaching technique, supplies an effective learning, so that the spectator sets the sequence of picture, making to emerge meaning according to his experience and cognitive structure.

Keywords: Science education. Narrative. Pictures in narrative. Teaching techniques. Interdisciplinarity.

${ }^{1}$ Licenciada e Bacharel em Ciências Físicas e Biológicas, doutora em Ecologia. Docente, Departamento de Educação, Instituto de Biociências, Universidade Estadual Paulista (Unesp), campus de Botucatu. Botucatu, SP, Brasil.<lpaleari@ibb.unesp.br>

${ }^{2}$ Licenciado em Geografia. Professor de Geografia aposentado, Escola Estadual "Professor Euclides de Carvalho Campos". Botucatu, SP, Brasil.

\footnotetext{
${ }^{1}$ Departamento de Educação, Instituto de Biociências, Unesp Caixa Postal 510

Distrito de Rubião Jr. - Botucatu, SP

18.618-970

491

Ciência : Ed Educação, v. 16, n. 2, p. 491-506, 2010
} 


\section{Narrativa, conhecimento humano e a prática de ensino}

Por meio de expressões pictóricas organizadas em cenas, cenários e suportes diversos, desde as pinturas rupestres em cavernas, o Homem conta e registra histórias sobre si e seu ambiente, revelando sentimentos, forma de pensar e de interagir no mundo (BAHN, 1998, PESSIS, 2003). O mesmo verifica-se na tradição oral de diferentes povos, que, por meio de narrativas, por vezes simples, intrigantes, metafóricas, transmitem os principais traços culturais aos descendentes, preservando as respectivas identidades dos grupos. Somos, ao mesmo tempo, protagonistas das nossas histórias pessoais, e coadjuvantes, na interação com o meio biótico e abiótico que nos cerca, na construção da história evolutiva da humanidade.

Desde tenra idade as narrativas nos acompanham, seduzindo-nos pelo poder que têm de nos permitirem seguir por caminhos inusitados, fazendo-nos deparar com o imprevisível, com o surpreendente, o fantasioso, o criativo. As histórias faladas e musicadas, contos infantis e canções de ninar, não só são conhecidos pelo poder de envolver afetivamente as crianças ao narrador, como por aguçar-lhes a imaginação e curiosidade, aspectos importantes para o desenvolvimento emocional e cognitivo.

Contudo, o domínio que os modelos explicativos lógico-matemáticos, oriundos da física, exerceram no meio científico desde o século XVII definiu a nossa forma objetiva de conceber o mundo, marginalizando o pensamento narrativo e todas as contribuições advindas de investigações baseadas nessa abordagem. Nas Ciências Biológicas, por exemplo, as investigações fundadas na físico-química, como a biologia molecular, a biofísica e a bioquímica, floresceram com enorme destaque e aceitação em detrimento das metodologias históricoevolutivas, as quais, de acordo com Mayr (2005), encontram-se mais próximas das ciências humanas, marcadas fundamentalmente por abordagens interpretativas (DENZIN e LINCOLN, 1994). No entanto, a mudança paradigmática que teve como marco epistemológico a Teoria Biológica do Conhecimento (MATURANA e VARELA, 1980,1995) assume o observador - até então considerado impressionável por estímulos ambientais - como agente que experimenta e explica a sua própria experiência de forma autorreferencial. Uma espécie que se inter-relaciona por meio do linguajar, uma conversação baseada na linguagem e na emoção (MATURANA, 2001). Com essa mudança de foco, a narrativa transformou-se em tema de grande relevância em diferentes áreas do conhecimento, quando se m questões relativas à construção de significado na experiência humana (RUIZ, 1996, 2003; GIEDT, 1997; MARSHA, 2002; NORMAN, 2006; BUTCHER, 2006; KLERFELT, 2006; SERIG, 2006).

O pensamento narrativo e sistêmico, como assim o entendem, respectivamente, Bruner $(2000,1997)$ e Maturana e Varela (1995), é a maneira mais antiga e fundamental de as pessoas atribuírem sentido às experiências, que podem ser revisitadas em tempo e local distintos, quando apelamos para a memória. Diferente do pensamento caracterizado por abstrações lógico-matemáticas, empregado com interesse na explicação causal de princípios gerais da Natureza, o pensamento narrativo refere-se, segundo Bruner (1997), às intenções e ações humanas. Portanto, por meio dele, podemos revelar e identificar mundos interiores e resignificar as nossas vidas.

Considerando que a narrativa apela para a imaginação, permitindo-nos formar imagens mentais do que é experimentado e de situações jamais vivenciadas, Egan (1994, 2002) assume-a como um poderoso e negligenciado recurso didático aplicável à educação infantil. 
Para esse autor, crianças de tenra idade já possuem ideias e conceitos abstratos, que são usados com propriedade, revelando compreensão, mesmo sem ainda serem capazes de verbalizá-los em explicações. Nesses esquemas mentais abstratos, conceitos em oposição binária, que em grande medida podem ser enquadrados na categoria do conhecimento estético, baseado na experiência, na emoção (TAYLOR, FISHER e DRUFRESNE, 2002) - como bem-mal, liberdade-opressão, coragem-covardia -, seriam fundamentais para a compreensão de novos contextos, conceitos e ideias complexos (EGAN, 1994, 2002). Crítico de propostas curriculares que ignoram essa característica do pensamento narrativo, Egan (1994) atribui tal situação ao domínio de ideias como as de Piaget, que definem etapas no desenvolvimento cognitivo das crianças baseadas na aquisição do pensamento lógico-matemático, que ocorre mais tardiamente no seu desenvolvimento. Desta forma, a aquisição do conhecimento é assumida como avançando do concreto para o abstrato, do simples para o complexo, do conhecido para o desconhecido, da manipulação ativa para a conceituação simbólica, princípios esses que, segundo Egan, não podem ser aceitos universalmente como verdadeiros, haja vista a aprendizagem da língua, por exemplo, que é adquirida muito cedo e é muito complexa e abstrata.

\section{A proposta: contexto, objetivos e etapas do desenvolvimento}

Com um longo histórico de fragmentação, hierarquia e especialização, empreendimentos humanos de natureza científica, educativa e empresarial investem hoje em estudos e no desenvolvimento de propostas que rompam com os limites disciplinares.

No entanto, abandonar a antigas práticas é tarefa árdua, porque a sua base de sustentação, calcada sobretudo nos fantásticos avanços científico-tecnológicos, alimenta desde a realização facilitada de trabalhos pesados, por meio de equipamentos mecânicos e eletroeletrônicos, até o desejo de vida duradoura, na medida em que avançam os conhecimentos biológicos de aplicabilidade na agricultura, nutrição e medicina.

Não obstante todas as conquistas, muitos fenômenos cruciais à compreensão de mundo e de nós mesmos como espécie que pensa, constrói e lê história, continuam distantes de uma base explicativa satisfatória e coerente. Longe de podermos abdicar dos conhecimentos especializados, demo-nos conta de que precisamos acrescentar a eles novas metodologias e instrumental em busca de superarmos o desafio imposto pela complexidade que é inerente à Natureza. Demo-nos conta de que precisamos pensar também o todo - que é mais do que a soma de partes - de forma integrada, sistêmica e aproximar profissionais das diferentes áreas do conhecimento em abordagens inter e transdisciplinares (D'AMBRÓSIO, 1997; NICOLESCU, 1999, 2000). Essa necessidade é extensiva ao Ensino Fundamental e Médio, nos quais não só a estrutura disciplinar, mas também o despreparo de professores, ainda divide o conhecimento em aulas, em práticas e em interpretações estanques, que, gradativamente, esfacelam o mundo único, lúdico e fascinante das crianças, em salas desaparelhadas e atividades desinteressantes, que não fazem jus à curiosidade e potencialidade intelectual que elas possuem.

Os aportes teóricos apresentados, que destacam a narrativa como elemento de significação de experiências humanas, serviram de suporte para este estudo, que contou ainda com dados de uma pesquisa em ecologia sobre interações multitróficas, desenvolvida na Ilha de Marajó (PALEARI, 1997), e com conhecimentos secioculturais reunidos pela autora deste 
estudo, durante três anos, como moradora da cidade de Salvaterra. De posse desses conhecimentos, a proposta foi elaborada e uma viagem a Salvaterra aconteceu com o propósito de realizarmos filmagens que retratassem aspectos socioculturais, paisagísticos e das interações multitróficas, como a que Paleari (1996) adaptou para o público infanto-juvenil. Dessas filmagens em Salvaterra, Marajó, resultou uma edição de vídeo de 12 min, com imagens em narrativa, portanto, sem texto falado, para que os alunos fizessem um tipo de viagem ao local. $\mathrm{O}$ objetivo dessa produção foi o de utilizá-la para verificar as possibilidades pedagógicas da narrativa como instrumento de ensino em sala de aula, nos moldes propostos por Egan (1994); e, também, de servir como tema desencadeador de uma proposta interdisciplinar que envolveu e integrou professores de Ciências, Geografia e História, bem como 32 alunos de uma $6^{a}$ série ( $7^{\circ}$ ano) da Escola Estadual "Professor Euclides de Carvalho Campos", na cidade de Botucatu, interior do Estado de São Paulo, durante o ano letivo de 1999.

$\mathrm{Na}$ primeira etapa deste trabalho buscamos estimular o imaginário e o resgate de conhecimentos prévios dos alunos, por meio de uma atividade intitulada: Imaginando Marajó. A ela seguiu-se a segunda etapa, com a apresentação do vídeo de 12 minutos, especialmente preparado para conhecimento daquela realidade marajoara.

\section{Imaginando Marajó}

Dos 32 alunos integrantes da classe de $6^{a}$ série, 28 estiveram presentes a esta atividade. Organizaram-se em nove grupos, oito de três e um de quatro integrantes, para representarem, em um cartaz, na forma de desenho, a Ilha de Marajó. Partiu-se, para isso, do pressuposto de que os pré-adolescentes colocariam, em suas gravuras, características representativas daquilo que têm como importante e sabido, aspectos do imaginário e dos conhecimentos já adquiridos, sobre a Ilha de Marajó, um local que nunca fora visitado por eles.

Ao final dessa etapa, um aluno de cada grupo, de posse do cartaz elaborado, apresentou oralmente o respectivo trabalho, com liberdade para acrescentar informações e esclarecer dúvidas e curiosidades dos colegas, sobre as concepções reveladas a respeito da Ilha de Marajó.

Por que especificamente a Ilha de Marajó?

Em primeiro lugar, porque ela satisfaz a algumas das condições presentes na proposta de Egan (1994) a serem testadas, que se referem ao ambiente e aspectos socioculturais bastante distintos daqueles que fazem parte da vida dos alunos de Botucatu.

Marajó é uma ilha do Norte do Brasil $\left(0^{\circ}\right.$ e $2^{\circ} \mathrm{S} / 48^{\circ} 20 \notin$ e $\left.51^{\circ} \mathrm{W}\right)$ pertencente ao Estado do Pará, com cerca de 49 mil km². Situada ao nível do mar, apresenta relevo dominado por planície, com um bioma de savana a leste (local das filmagens) e outro de floresta tropical úmida a oeste. É banhada pelo Oceano Atlântico e pelas águas dos rios Amazonas, Tocantins e Pará, que deságuam na baía de Marajó. Possui clima quente e úmido, população basicamente autóctone, com aproximadamente 250.000 habitantes (IBGE, 2001). O ambiente é marcado por barcos, pescadores, flora e fauna peculiares, poucos veículos automotores e economia marcada pela exploração do pescado e do turismo.

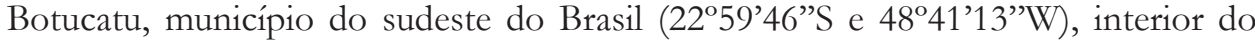
Estado de São Paulo, possui uma área territorial de 1.482,87 km² e um total de 103.793 habitantes na área urbana (IBGE, 2001). Situa-se na Cuesta Botucatu, a uma altitude aproximada 
de oitocentos metros e caracteriza-se por possuir ruas íngremes (Figura 1) e clima subtropical, com invernos rigorosos e secos. O município possui grande extensão de áreas de pastagem e poucos remanescentes de floresta estacional semidecidual e de vegetação de cerrado. Destacase pela presença de uma universidade pública estadual, que atrai grande população externa, parte da qual permanece na cidade basicamente durante o curso universitário, e alimenta economia baseada em especulação imobiliária e exploração do comércio.



Figura 1. Aspectos gerais do município (A) e da cidade (B, C, D) de Botucatu.

Esclarecendo ainda sobre a escolha da ilha para desenvolver esta proposta, deve-se acrescentar o fascínio que Marajó costuma exercer em adolescentes e adultos, dada a sua grande extensão, e localização na foz do Rio Amazonas. Este é outro referencial geográfico de importância a estimular o imaginário das pessoas, pela sua magnitude e papel histórico no desbravamento da Amazônia, que teve aspectos gerais e da flora e fauna retratados inicialmente em importantes obras de naturalistas do século XVIII (BATES, 1979; WALLACE, 1979 edições brasileiras de originais ingleses datados de 1886 e 1889, respectivamente).

Os dados gerais sobre a ilha propiciam um pensamento complexo, abordagem sistêmica e interdisciplinar com base na compreensão de conceitos e ideias centrais que podem ser ligados em rede de significados com o desenrolar de atividades selecionadas para isso, estimulando uma compreensão de contextos, de totalidade. 


\section{Salvaterra, Ilha de Marajó: imagens em narrativa}

As imagens apresentadas aos alunos foram tomadas desde o porto de Belém, na baía do Guajará, até a cidade de Salvaterra $\left(45 \notin 12 \notin \notin 0^{\circ} \mathrm{S}\right.$ e $\left.48^{\circ} 31 \not 0 \notin \notin \mathrm{W}\right)$, em novembro de 1997 (Figura 2). As gravações, especialmente preparadas para este estudo, foram editadas em uma sequência de imagens em movimento sem locução de texto. De início, elas transportam o espectador para dentro de um barco do tipo gaiola (Figura 2-A), comum, na região norte do Brasil, junto a grupo de viajantes com traços fisionômicos predominantemente indígenas (Figura 2-C, N, O, P), distintos daqueles exibidos pelos adolescentes da $6^{\mathrm{a}}$ série, descendentes, sobretudo, de italianos e portugueses. Prosseguem tomadas das margens da baia do Guajará, seguidas pelas da baía de Marajó, com a exibição de palafitas (Figura 2-B) e uma vegetação exuberante repleta de açaizeiros - palmeira característica da região, de cujos frutos se extrai o açaí, bebida muito apreciada pelos nativos e que, hoje, já é comercializada nas cidades de São Paulo. A chegada à ilha é feita por meio de uma tomada de longa distância, revelando a aproximação paulatina do barco até o ancoradouro, o qual é divisado, posteriormente, do lado de fora, em toda a sua extensão (Figura 2-A), manobrando para o aporte. Dele, repletos de bagagens, descem os passageiros (Figura 2-D), que se encaminham para ônibus e carros antigos, e seguem viagem por uma estrada ladeada de árvores (Figura 2-F), vegetação rasteira e casas esparsas, predominantemente feitas de taipa e madeira. Um cenário típico da Ilha de Marajó, apresentado em imagens tomadas de dentro de uma das conduções em movimento pela estrada. Em determinado momento, chega-se a um povoado com poucas pessoas na rua (Figura 2-G). Cenas de uma vida bucólica, marcada pelo despojamento das casas, e das pessoas transitando a pé e de bicicleta, trazem também outros aspectos característicos, como a flora e a fauna locais - grandes árvores e palmeiras, insetos, urubus, peixes e o búfalo, integrados em diversos tipos de interações ecológicas. Em certo momento, três adolescentes típicos (Figura 2-N, O) são interpelados, na rua, pela cinegrafista que, detrás da câmera, pergunta-lhes os nomes. O som do vídeo, que até então só reproduzira breves momentos de vento, o burburinho no barco e o som das ondas que lhe roçavam o casco durante o trajeto, é aberto quando um desses meninos responde, dizendo o seu nome e o nome dos dois colegas. Novamente sem som, as imagens revelam, na cidade, um carro que entra em uma curva e faz breve trajetória ao lado de uma pequena enseada, onde pescadores trabalham na sua rotina dentro de dois barcos (Figura 2-S), que balançam ao sabor do vento. O vídeo termina na rua principal da cidade, levando o espectador até um cais à beira do rio Paracauari, onde a tomada de imagem é fechada em um muro decorado com traços característicos da arte Marajoara em cerâmica, que emolduram o nome da localidade: "Salvaterra, Ilha do Marajó" (Figura 2-U).

Antes da apresentação dessas imagens, que aconteceu em uma sala especial da escola para onde os alunos foram transferidos antes da exibição, apenas informamos que assistiriam a um vídeo sobre a Ilha de Marajó. Esta atividade aconteceu na aula posterior àquela na qual haviam realizado a atividade "Imaginando Marajó".

Após os 12 minutos de duração dessa apresentação, os alunos puderam destacar e comentar as observações feitas, elaborando um texto escrito sobre as suas percepções.

Não houve qualquer solicitação para que reapresentássemos o vídeo. 
Imagens em narrativa: contraposição cultural ...
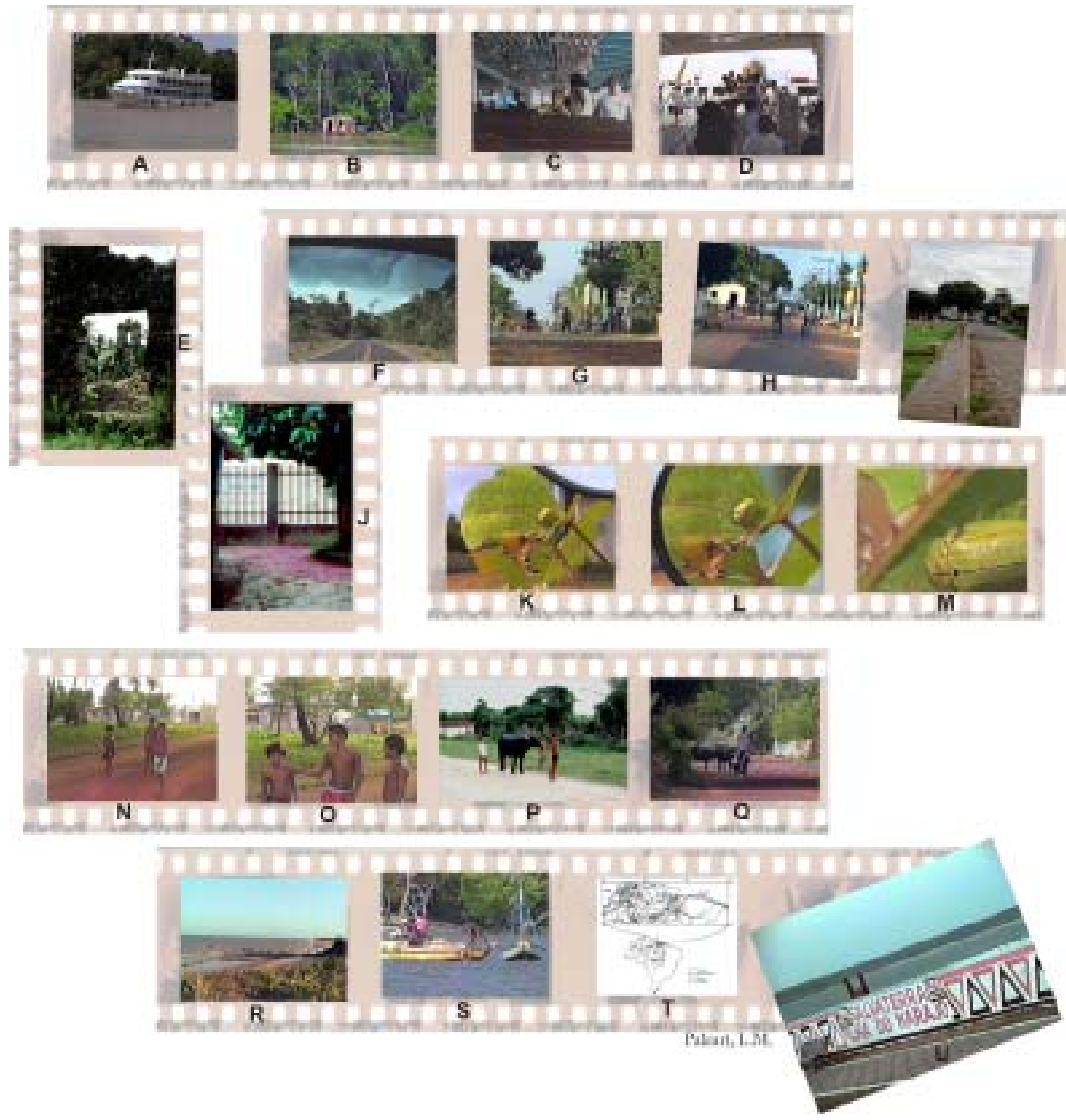

Figura 2. Fotogramas representativos de uma filmagem preparada para apresentação de aspectos da porção leste da llha de Marajó: Barco do tipo gaiola, que é utilizado no transporte de passageiros (A); palafita e vegetação com muitos açaizeiros, na margem do curso d'água (B); passageiros no interior do barco (C); desembarque de passageiros em Marajó (D); ruínas de construções do século XIX (E*); aspectos da estrada e vegetação no interior da Ilha (F); aspectos da vida cotidiana de marajoaras $\left(\mathrm{G}, \mathrm{H}, \mathrm{I}^{\star}\right)$; árvore frutífera típica da região - jambeira -, em flor $\left(\mathrm{J}^{*}\right)$; inseto fitófago em planta ruderal comum na região $(\mathrm{K})$; detalhe de inseto fitófago com parasitóide no dorso em forésia $(\mathrm{L}, \mathrm{M})$; adolescentes marajoaras $(\mathrm{N}, \mathrm{O})$; búfalo no convívio com moradores $\left(P^{*}, Q\right)$; aspecto de uma praia na Baía de Marajó $(R)$; pescadores trabalhando nas embarcações (S); localização geográfica da ilha $\left(T^{*}\right)$; imagem final da filmagem identificando a cidade de Salvaterra $(U)$. * fotogramas que não fazem parte do vídeo editado para este estudo, mas que foram apresentados posteriormente aos alunos da $6^{a}$ série participante.

\section{Parâmetros para a análise dos dados coletados}

Os nove cartazes produzidos pelos alunos (Figura 3), complementados com os dados das respectivas apresentações orais, e os textos produzidos por eles após assistirem ao vídeo foram analisados considerando-se:

- O que os alunos comunicaram inicialmente sobre a Ilha de Marajó?

- Qual o significado das gravuras e das histórias escritas, quando interpretado pela óptica da sociedade e cultura desses pré-adolescentes? 
Paleari, L. M.; Biz, A. C.

- Entre as expressões dos diferentes alunos, o que houve de elementos comuns (contraditórios ou não) originários de conhecimento prévio ou de componente do imaginário?

- Quais as diferenças marcantes entre os dois momentos: Imaginando Marajó e Relatando sobre Marajó, após viagem propiciada pelas imagens apresentadas em vídeo?

\section{Resultados e discussão}

Os desenhos apresentados na atividade "Imaginando Marajó" (Figura 3), seguidos das respectivas explicações e dos esclarecimentos orais sobre as representações, revelaram que, para todos os alunos, ilha era um lugar que se erguia das águas, em geral como um monte, relativamente ermo e longínquo. Nesse cenário, os elementos comuns a todos os trabalhos foram aves em pleno voo e o sol, o qual aparece radiante em oito cartazes. O único que traz um sol esmaecido (Figura 3-G) é, também, o único a não ter, pelo menos, uma palmeira representada, apenas notáveis pássaros em voo e caudas expostas de tubarões, ao redor da ilha, como sentinelas. Em apenas três cartazes o ser humano foi integrado à paisagem (Figura 3-A, B, C). Em cada um dos dois primeiros, há uma pequena figura de pessoa pescando, acompanhada de outra, na Figura 3-A, sentada sob uma árvore.

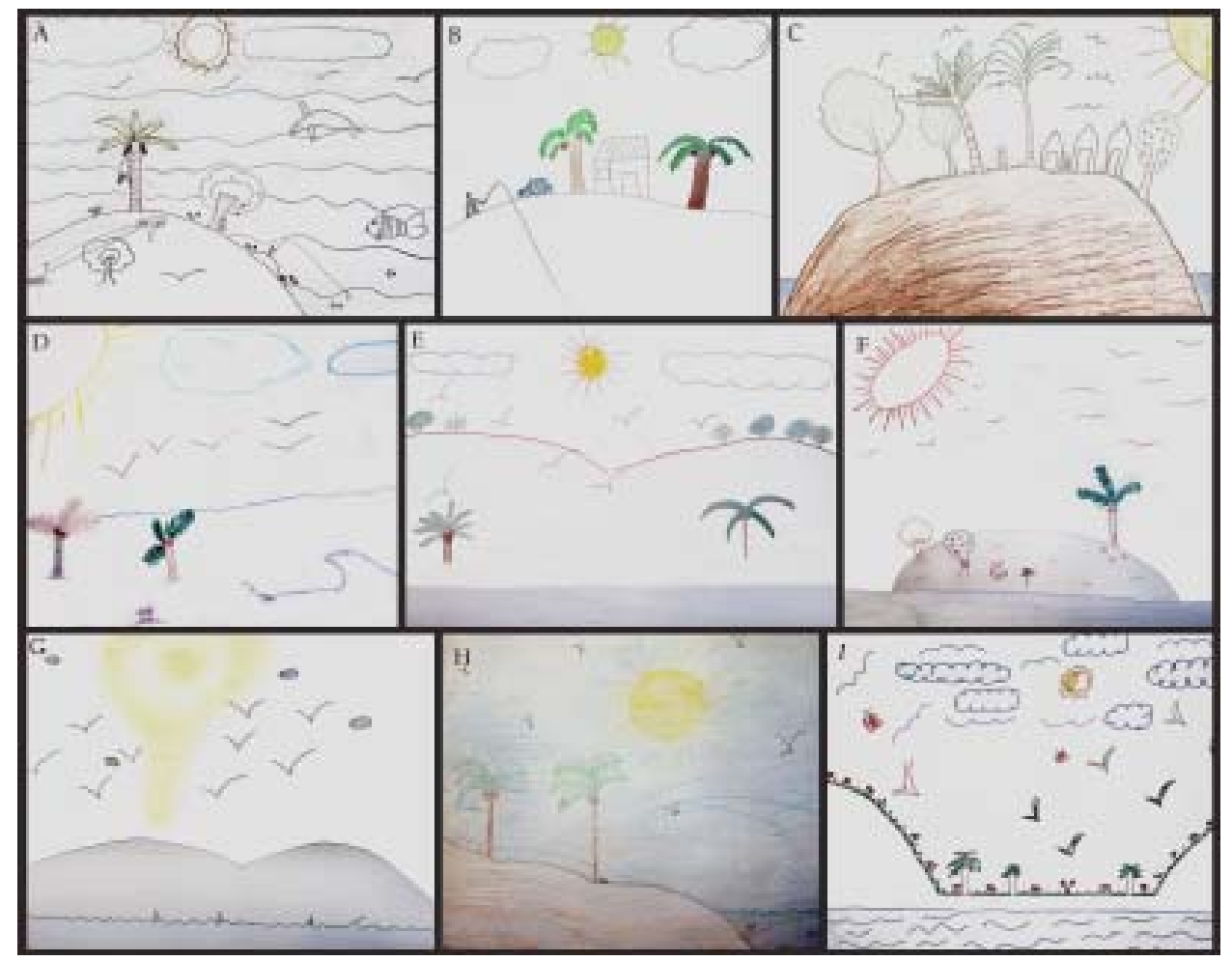

Figura 3. Desenhos feitos por grupos de alunos da $6^{\mathrm{a}}$ série participante deste estudo, representando suas concepções da llha de Marajó. 
Ilha como "uma porção de terra cercada de água por todos os lados" é a definição normalmente apresentada às crianças no início do Ensino Fundamental, e que elas memorizam e usam toda vez que precisam expressar conhecimento sobre o assunto. As histórias e representações encontradas em muitos livros infanto-juvenis não só reforçam essa definição, como são fundamentais para a consolidação de conceitos e ideias de ilha como um monte cercado de água por todos os lados, desabitado e inóspito. Em geral, de difícil acesso, distante do mundo civilizado, repleto de mistérios, náufragos e tesouros enterrados, mas pode ser também uma ilha da fantasia, a representar a beleza, repleta de luz e cor, como sugere o desenho da Figura 3-I. Qualquer que seja a fantasia, mistério ou paraíso, é marcante o caráter silvestre da paisagem. Mesmo quando incluída a figura humana (Figura 3-A, B, C), nenhuma alusão oral foi feita a ela ou à presença de cidades, indústrias ou de plantações. No entanto, pode-se observar que na, Figura 3-A, um trecho de rede elétrica foi representado, com postes e fios, contrastando com a paisagem campestre.

A análise das redações, elaboradas após a exibição das imagens em narrativa sobre a Ilha de Marajó, reforçou a existência dos conceitos prévios e ideias já apontados. Porém, nesse momento, após se surpreenderem com a realidade de uma ilha relativamente populosa e agradável, escreveram:

"Na ilha de Marajó nós vimos que tem vida. Vimos que tem coqueiros e muitas árvores. Lá tem pessoas [...]"

"Numa ilha todo mundo pensa que só tem coqueiro, é mentira tem várias coisas como: [h]abitantes, pássaros, flores, animais, árvore."

"Nós todos imaginamos uma ilha só com palmeiras, mas agora deu para perceber que não é nada disso."

"Nessa ilha existem muitas belezas naturais. [...] Essa ilha não é deserta. Muitas pessoas moram lá."

"Na ilha de Marajó eu não tinha pensado que tinha várias casas, árvores no meio do asfalto."

"Todos pensam que uma ilha então é pequena, não anda carro, não tem muita casa, como se fosse uma floresta ou então uma ilha deserta."

"A ilha de Marajó não é do jeito que eu pensava. Eu achava que lá nem se[ ] quer [h]avia população, me enganei $[. .$.$] "$

"Na Ilha de Marajó existe[m] muitas coisas que en não sabia[,] por exemplo: Eu não sabia que todos os moradores eram morenos, existem carros e muitas coisas que temos aqui."

“... tem muito pescador, tem o vento. [...] tem ainda carroça, boi [búfalo] andando na rua isso é muito legal." 
Paleari, L. M.; Biz, A. C.

"Eu aprendi que não só porque é uma ilha não pode ter pessoas."

"Lá tinha de tudo bicicletas, cavalos, e o que eu achei mais interes[s] ante foi um bomem de bicicleta puchando[puxando] dois búfalos."

"O meio de transporte da ilha mais usado entre eles é a bicicleta."

"Nessa ilha também tinha meios de transporte, como carro, car $[\mathrm{r}]$ oşa, carro de boi, e bicicleta. Lá tem também animais como o urubu, gaivota, formiga etc."

Deve-se considerar que a força de uma narrativa não está apenas no seu tema, mas, antes de tudo, na força do componente imaginativo que propicia e que foi potencializado neste estudo por colocar as pessoas diante do inusitado, do contraditório e da não linearidade das imagens. A partir daí, a abstração característica do pensamento narrativo de cada espectador, em busca da construção de significados, define uma sequência de imagens que, de acordo com Ruiz (1996), é feita por meio de analogias, semelhanças de conteúdos e tonalidades emotivas próprios. Desta forma, foram compreendidos os 32 textos, $75 \%$ deles com conteúdo interpretativo e $25 \%$ predominantemente descritivos (Tabela 1). Do total, $90,62 \%$ destacaram a presença de humanos ou de seus artefatos e $81,25 \%$ chamaram a atenção para plantas e animais presentes, tecendo diversos tipos de considerações sobre seus aspectos morfológicos e interações. Não se esperava que a população humana em seu cotidiano, por ser um aspecto comum a qualquer ambiente urbano, chamasse tanto a atenção dos alunos. No entanto, esse aspecto se contrapôs frontalmente ao que traziam no imaginário: ilha, como um lugar desprovido de áreas urbanas e povoado apenas por certos animais e plantas.

Tal constatação implicou a revisão e necessidade de reelaboração dessa construção, um processo de resignificação de conteúdo. Considera-se que, mesmo o fato de terem dado

Tabela 1. Relação de títulos das narrativas escritas pelos alunos da $6^{a}$ série $(N=32)$ sobre apresentação que assistiram sobre a llha de Marajó.

\begin{tabular}{ll}
\multicolumn{1}{c}{ Descritiva (25\%) } & \multicolumn{1}{c}{ Interpretativa (75\%) } \\
\hline A Terra de Marajó & Ilha encantada \\
Ilha de Marajó & Contando sobre ilha de Marajó \\
As coisas da ilha de Marajó & A cidade de Marajó e o que a [há] lá \\
A llha de Marajó & Ilha do sonho \\
Viva ilha de Marajó & A ilha de Marajó \\
A llha & A llha do mistério \\
Livro & A beleza da llha de Marajó \\
A llha de Marajó & Bem vindo a [à] ilha do Marajó \\
llha de Marajó & A filha de Marajó \\
Ilha de Marajó & Expedissão [expedição] na llha de Marajó e na cidade de Salvaterra \\
Um[a] ilha tão bonita & Uma viagem na ilha de marajó \\
A llha de Marajó & Marajó e seus habitantes \\
Águas frias & A llha de Marajó \\
A llha de Marajó & Ilha de Marajó \\
& A Grande ilha de Marajó \\
& Título de história inexistente \\
& Aprendendo Marajó \\
\hline
\end{tabular}


Imagens em narrativa: contraposição cultural ...

ênfase à presença de plantas e animais, tenha sido resultado de processo semelhante, uma vez que são mais abundantes e exuberantes na área urbana de Salvaterra, do que no município de Botucatu. Portanto, ilha como sinônimo de um lugar descampado, sem cidades, que serviu como referência, guiou a seleção das imagens colocadas em destaque pelos alunos, cujas considerações sobre elas são reveladoras das analogias e dos significados estabelecidos por eles.

Verificou-se ainda que $25 \%$ dos alunos explicitaram os marajoaras como humildes e pobres, e outros $25 \%$, de um total de $34,37 \%$, como caçadores (pescadores -coletores), referindo-se ao despojamento das pessoas e simplicidade do ambiente urbano (Figura 2). Na visão desses alunos, que também pertenciam a uma classe social humilde, mas de pessoas brancas, andar descalço, com pouca roupa no corpo, ser magro, viver em uma cidade simples, pouco urbanizada e ter cor morena ou negra, era sinônimo de pobreza. Para eles, essas características permitiram interpretar que em Marajó

"A maioria das pessoas tem pouco dinheiro por isso eles comem os frutos das árvores e comem o peixe colbido pelo homem da pesca."

"Lá não [h] á forsa[força] elétrica as lâmpadas são de Lampião e a comida é feita no fogão a [à] lenha."

"Mas o povo dessa ilha até que tem alguns confortos, eles não vivem como os indios de antigamente lá tem meios de transporte, energia elétrica, casas como as nossas, algumas são um pouco diferente."

Como se pode perceber, há um componente subjacente aos pensamentos conscientes, que deve dificultar a resignificação dos conhecimentos. Supor o uso de lampião e de fogão à lenha, aos quais nenhuma alusão foi feita nas imagens em vídeo, assim como atribuir aos índios falta de conforto, indica a força de certos componentes adquiridos socialmente na construção da narrativa pessoal. Interpretações tendem a se manter baseadas no conjunto de condicionamentos de princípios culturais assumidos, que, para Bohm e Peat (2000), são componentes tácitos que determinam padrões de pensamento e de condutas, muitas vezes responsáveis por dificultar avanços pessoais e, até, por fixar relações sociais conflituosas. Ele considera que, quando o contato de uma pessoa com o ambiente físico é maior, a sua atenção tende a voltar-se para ele e a sua consciência move-se além do tempo e dos interesses limitados de um grupo social particular, no sentido de certa conexão com a totalidade. Hoje, mais distantes desse ambiente, temos a Filosofia, Ciência e religiões, ocupando-se de nos oferecer tal sentido de pertencimento e de totalidade. Contudo, invariavelmente, isso acontece por meio de verdades absolutas, que, de acordo com Bohm e Peat (2000), tolhem a criatividade e dispõem a mente a nunca ceder, não importando quantas evidências possam ser apresentadas em contrário. O resultado nessas situações, de acordo com ele, são os conflitos, as guerras e uma espécie mais vulnerável. Portanto, é premente a necessidade de se investir em uma educação infantojuvenil, que valorize o autoconhecimento e abordagens transdisciplinares. Professores de diferentes disciplinas, inteirados de resultados como esses, podem discutir e elaborar estratégias para favorecer o diálogo, ajudando cada adolescente a perceber e aceitar as diferenças culturais como componentes importantes da diversidade humana, tão legítimos, respeitáveis e valorosos quanto os seus próprios. E, para isso, é fundamental que, de início, sejam elaboradas 
Paleari, L. M.; Biz, A. C.

atividades integradas, interdisciplinares, como sugerem os Parâmetros Curriculares Nacionais (BRASIL, 1998), tanto no tratamento do conteúdo a ser desenvolvido com os alunos, como também no estudo, discussão e elaboração de propostas e estratégias de ensino-aprendizagem entre professores de diferentes disciplinas.

Entrementes, foi interessante constatar que, mesmo aquelas visões estereotipadas, que em geral levam à rejeição de pessoas com base em aparência e em avaliações superficiais, não se mantiveram incólumes. O que seria motivo de discriminação, vergonha e infelicidade para quem escreveu que

"Lá ninguém tem vergonha andão [andam] sem calcado só com uma simples bermuda e ... têm pouco dinheiro por isso eles comem os frutos das árvores e comem o peixe colbido pelo $[\mathrm{s}]$ homens da pesca",

acabou sofrendo uma perturbação, ao perceber que tal condição não afetava, da mesma forma, aos marajoaras, os quais pareciam felizes, conforme explicitado claramente na frase:

"As crianças eram muito diferentes, simples, de [pele] morena, mas elas pareciam felizes".

O cérebro como sistema - com circuitos nervosos a definir formas de pensamento e memória, que eliciados desencadearão uma série de reações com produção de substâncias diversas determinantes de comportamentos particulares - é plástico, isto é, ao longo da vida e de acordo com o tipo e grau de estimulação, tem a capacidade de estabelecer diferentes conexões, tanto por meio de novos arranjos de neurônios em trajetos inéditos como por meio do desenvolvimento de maior número de dendritos (BOHM, 1994; KOLB e WHISHAW, 2002). Essa plasticidade, presente em toda a vida de uma pessoa, é potencialmente maior durante infância e adolescência e, por essa razão, com as melhores condições de ter alterado o seu padrão de rede e, consequentemente, maior probabilidades de que se alterem comportamentos preestabelecidos e que as pessoas se abram não só para a aceitação do diferente, como para as possibilidades de serem diferentes, entendendo-se melhor e o meio onde vivem.

Destaque a moradores felizes e a Marajó como um lugar calmo, gostoso de viver, foram apresentados por $21,9 \%$ dos alunos. Para 31,25\% deles, a ilha é bela e isso se deve aos aspectos paisagísticos. Portanto, não houve apenas o reconhecimento da diversidade de modos de vida e valores, houve a interpretação de que é possível ser diferente daquilo que uma certa sociedade define como padrão, e, ainda assim, ser feliz. Em um processo de ensinoaprendizagem, uma situação como essa é propícia para estimular discussões sobre padrões sociais, emoções e liberdade de ser, que podem contribuir para o desenvolvimento de visões mais críticas e autoconhecimento, ampliando as possibilidades de desenvolvimento de uma mente imaginativa e criativa. Mas, para isso, é preciso que haja educadores preparados para o que Caine (2004) classificou como professor de orientação-3, aquele que ensina dentro de um padrão elevado de qualidade, por meio de abordagens multidisciplinares e experiências complexas que alia aos interesses dos alunos, porque é alguém capaz não apenas de perceber as inter-relações, mas de trabalhar com as possibilidades que inevitavelmente emergem durante um processo de ensino-aprendizagem como esse.

Os alunos da $\sigma^{a}$ série, trazendo um dado de conhecimento prévio, e contraditório com relação às representações que fizeram em desenhos, referiram-se à grande extensão da ilha em 
quilômetros quadrados, com a observação de que se trata da maior ilha do mundo - informação esta que, para eles, representava apenas algo relativamente grande, já que não tinham dimensão do que fossem $50.000 \mathrm{~km}^{2}$. Tanto isso é fato, que as cenas das imagens apresentadas em vídeo, feitas de dentro de um veículo em movimento, mostrando aspectos do interior da ilha, serviram como referência para suas analogias. Aquele caminho, percebido por eles como longo, porque permitia ainda divisar o horizonte, dando a sensação de amplitude devido ao baixo relevo da ilha e ausência de edificações, não encontrou equivalente nos "montes de terra cercados de água por todos os lados", representados nos desenhos (Figura 3). Dessa forma, concluíram que a ilha é, em realidade, grande. Tendo conhecimento desse fato, é possível auxiliar os alunos a conseguirem melhor aproximação do que representa esse valor de 50 mil km², planejando e integrando atividades de medição com cálculos de área, escala e construção de maquetes.

O outro conhecimento prévio evidenciado foi a interpretação correta que fizeram a respeito dos tipos de interações existentes entre seres vivos, a partir de imagens de insetos em atividades: a) uma pequena abelha alçando voo de dentro de uma flor (consumidor - obtenção de néctar), b) um besouro depositando ovos sobre uma folha (herbivoria), c) vespinha, inicialmente pousada no élitro de um besouro, sendo carregada por ele e, posteriormente, pousada sobre uma desova dessa mesma espécie (Figura 2 K,L,M), que identificaram como vespinha "predadora" (parasitóide), e d) formigas percorrendo um ramo de planta para dela se alimentarem (consumidor). Apenas um aluno referiu-se ao besouro fitófago como praga, resultado que merece atenção, porque esse é um conceito muito difundido e que costuma estimular e sustentar atitudes hostis com relação a determinados seres. O conceito de praga é humano e, tecnicamente, relativo a nível econômico de dano. Segundo essa definição, ele só se aplica quando animais ou plantas, buscando sobreviver, alimentam-se e reduzem em demasia (abaixo do nível de ganho econômico) o que os humanos cultivam para uso pessoal. De forma mais ampliada passou-se a utilizar o termo para todo ser vivo, animal ou vegetal, indesejável aos interesses humanos ou que ocupe um local que nos seja inconveniente. Portanto, é preciso rever com os jovens essas questões, como condição para que interpretem mais adequadamente o ambiente, e ajam de maneira mais coerente com a dinâmica dos ecossistemas, com os princípios conservacionistas e com nossas necessidades, para continuidade como espécie.

Esses três conjuntos de resultados discutidos até aqui, organizados a partir daquilo que os alunos destacaram sobre a Ilha de Marajó, são indicativos das amplas possibilidades que um tema ecológico oferece para o desenvolvimento de conteúdos de diferentes áreas do conhecimento, de forma interdisciplinar. Os próprios alunos, procurando explicar a presença de moradores morenos na Ilha de Marajó, levantaram a possibilidade de tal fato ser devido a receberem muito sol, ou serem descendentes de negros ou de índios. Tomando esses registros e lançando-os na forma de hipóteses a serem investigadas, ou problemas a serem solucionados, poder-se-á trabalhar conteúdos sobre a localização geográfica da área (relações com a incidência solar e clima) e ocupação do local (colonização e hereditariedade). Neste caso, podem-se destacar as diversas contribuições genéticas que deram origem ao povo brasileiro, $\mathrm{O}$ que incluirá, com procedência, abordar aspectos históricos da chegada do Homem ao continente americano e a posterior colonização marcadamente portuguesa. Com esse tratamento contextualizado e estimulando-se a investigação para construção de explicações coerentes, pode-se despertar maior interesse e envolvimento dos participantes. Trabalhar mudanças geomorfológicas a partir do rio Amazonas, correndo na contramão do seu curso atual, é estimular o interesse pelo passado geológico da Terra e compreensão da dinâmica planetária. 
Os descendentes de povos indígenas que estão na Amazônia vieram de onde? Que características possuem? Quais os seus hábitos de vida, inclusive alimentares? O que aconteceu com suas civilizações?

$\mathrm{Na}$ região Sudeste também temos descendentes de povos indígenas. Serão eles da mesma etnia? Passaram por situação semelhante às dos grupos da Amazônia? Onde estão eles nos dias de hoje? Como sobrevivem ao desmatamento e urbanização?

Essas também são questões que devem atrair os alunos para o conteúdo de história, que deixa de ser memorístico para fazer sentido frente às adaptações, dos diferentes grupos, a biomas específicos quanto à composição de flora, fauna, características geográficas, climáticas e alterações ambientais. A bibliografia, resultante das narrativas escritas pelos naturalistas que estiveram na região Amazônica (BATES, 1979; WALLACE, 1979), traz descrições de acontecimentos muito interessantes que permitem não só envolver os alunos, mas despertar-lhes o prazer pela leitura e interesse em compreender a História do Brasil.

As interações entre os insetos e destes com Ipomoea asarifolia, citadas por 46,87\% dos alunos, possibilitam desencadear o desenvolvimento de diversos conceitos de ecologia e de biologia do desenvolvimento, componentes do conteúdo programático de Ciências, que guardam certa relação com conceitos e ideias fundamentais de Geografia e História, como: densidade populacional, ocupação de hábitats, alterações ambientais, relações entre seres vivos (intra e interespecíficas), ecossistemas agrícolas etc. Dessa maneira, conteúdos contextualizados e trabalhados por meio de abordagem sistêmica, propiciarão envolvimento dos alunos em trabalhos investigativos, em sala de aula e no campo, com discussões enriquecedoras e construção de conhecimento pleno de significado. Isto foi o que se obteve no trabalho interdisciplinar desenvolvido com os professores de Ciências, História e Geografia (PALEARI, 2002), que foi desencadeado a partir dessas imagens, em narrativa e resultados ora apresentados.

Sendo a cognição dependente de uma rede que inexiste sem o ambiente, memória, experiências sensoriais e sociais, Maturana e Varela $(1980,1995)$ concebem-na como o próprio viver. Considerando ainda que o desenvolvimento cognitivo é estimulado por analogias, metáforas, suspenses e sentimentos, aspectos estes que uma boa narrativa comporta, há que se investigar profundamente e ampliar o diálogo, como advoga Herman (2000), entre as ciências cognitivas e o estudo das narrativas. Provavelmente, assim, consigamos construir um arcabouço conceitual satisfatório, inclusive para permitir aplicação eficiente da narrativa oral, escrita ou representada em imagens, em diferentes áreas como a da saúde e da educação, que já reúnem bastantes estudos empíricos.

\section{Conclusões}

Imagens em narrativa de um tema ecológico contrapondo costumes, valores e sentimentos envolvem adolescentes, estimulando-os a observações interpretativas, as quais propiciam abordagens sistêmicas, expressão e reelaboração de ideias e de conceitos, constituindose, dessa forma, em um excelente recurso didático, como teorizado por Egan (1994), possibilitando, ainda, o desenvolvimento de valorosas propostas interdisciplinares. 
Imagens em narrativa: contraposição cultural ...

\section{Agradecimentos}

Às professoras Claudete Pinto Pereira, Dercelina Helena dos Santos, Maria Augusta Silva

Leite Tomazetti, pela valiosa colaboração; e ao diretor da Escola Estadual "Professor

Euclides de Carvalho Campos", que nos abriu espaço para a realização do estudo.

\section{Referências}

BAHN, P. G. Illustrated History: Prehistoric Art. Cambridge: Cambridge University Press, 1998.

BATES, H. W. Um naturalista no Rio Amazonas. São Paulo: Edusp, 1979.

BRUNER, J. Atos de significação. Porto Alegre: Artes Médicas, 1997.

A cultura da educação. Lisboa: Edição 70, 2000.

BOHM, D. Thought as a system. London: Routledge, 1994.

BOHM, D.; PEAT, F. D. Science, order and criativity. London: Routledge, 2000.

BRASIL. Ministério da Educação e da Cultura. Secretaria de Educação Fundamental.

Parâmetros Curriculares Nacionais. Brasília: MEC, 1998.

BUTCHER, S. E. Narrative as a teaching strategy. The Jounal of Correctional

Education, Ashland, v. 3, n. 57, p. 195-208, 2006.

CAINE, G. Getting creativity, imagination and learning: releasing the imagination.

Independent School, Fredericksburg, v. 63, n. 2, p. 10-18, 2004.

D’AMBRÓSIO, U. Transdisciplinaridade. São Paulo: Palas Athena, 1997.

DENZIN, N. K.; LINCOLN, Y. S. Handbook of qualitative research. Califórnia: Sage

Publications, 1994.

EGAN, K. A narrativa como técnica de ensino. Lisboa: Publicações Dom Quixote, 1994.

A mente educada. Rio de Janeiro: Bertrant do Brasil, 2002.

GIEDT, J. F. A psychoneuroimmnological intervention in holistic nursing practice. Journal of Holistic Nursing, Thousand Oaks, v. 15, n. 2, p. 112-127, 1997. Disponível em:

$<$ http://jhn.sagepub.com/cgi/content/abstract/15/2/112>. Acesso em: 6 nov. 2003.

HERMAN, D. Narratology as a cognitive science. Image \& Narrative, Leuven, v. 1, n. 1, p. 1-24, 2000. Disponível em: <http://www.imageandnarrative.be/narratology/

davidherman.htm>. Acesso em: 18 jun. 2004.

IBGE. Instituto Brasileiro de Geografia e Estatística. Sinopse preliminar do censo demográfico 2000. Rio de Janeiro: IBGE, 2001. v. 7.

KLERFELT, A. Cyberage narratives: creative computing in after-scool centres. Childhood, Thousand Oaks, v. 13, n. 2, p. 175-196, 2006.

KOLB, B.; WHISHAW, I. Q. Neurociência do comportamento. São Paulo: Manole, 2002. 
Paleari, L. M.; Biz, A. C.

MARSHA, R. Narrative stories in adult teaching and learning. ERIC Digest, Washington, n. 241, 2002. Disponível em: <http://www.calpro-online.org/eric/docs/dig241.pdf>. Acesso em: 29 jul. 2005.

MATURANA, H. Cognição, ciência e vida cotidiana. Belo Horizonte: Editora UFMG, 2001.

MATURANA, H.; VARELA, F. Autopoiesis and cognition. Holanda: Dordrecht, 1980.

;___ A árvore do conhecimento: as bases biológicas do entendimento humano. Campinas: Editorial Psy, 1995.

MAYR, E. Biologia ciência única. São Paulo: Companhia das Letras, 2005.

NICOLESCU, B. Educação e transdisciplinaridade. Brasília: Unesco, 2000.

O manifesto da transdisciplinaridade. Brasília: Unesco, 1999.

NORMAN, R. Cultivating imagination in adult education. In: ANNUAL ADULT EDUCATION AND RESEARCH CONFERENCE, 1., 2002, Vancouver. Anais...

Vancouver: University of British Columbia, 2002. Disponível em: <http://www.edst.educ. ubc.ca/aerc/2000/normanr-web.htm>. Acesso em: 10 out. 2006.

PALEARI, L. M. Tamanho não é documento. Ciência Hoje das Crianças, Rio de Janeiro, v. 9, n.58, p. 8-9, 1996.

Partilha de recurso entre Botanochara sedecimpustulata (Fabricius, 1781) e Zatrephina lineata (Fabricius, 1787) (Coleoptera, Chrysomelidae, Cassidinae) em Ipomoea asarifolia (Convolvulaceae), na Ilha de Marajó, Pará, Brasil. 1997. 109f. Tese (Doutorado em Ecologia) - Instituto de Biologia, Universidade Estadual de Campinas, Campinas, 1997.

. Metodologia para uma abordagem sistêmica no ensino fundamental. In: REUNIÃO ANUAL DA SOCIEDADE BRASILEIRA PARA O PROGRESSO DA CIÊNCIA, 54., 2002, Goiânia. Anais... Goiânia: UFG, 2002. 1 cd-rom.

PESSIS, A. Imagens da Pré-História. São Paulo: FUMDHAM/Petrobrás, 2003.

RUIZ, A. La narrativa em la terapia post-racionalista. Disponível em: $<$ http://www. inteco.cl/articulos/002/index.html, 1996>. Acesso em: 14 jun. 2006.

La organización de significado que caracteriza la experiencia humana en la cultura occidental contemporânea. Disponível em: <http://www.inteco.cl/articulos/ 0019/texto_esp.html, 2003 >. Acesso em: 14 jun. 2006.

TAYLOR, S. S.; FISHER, D.; DRUFRESNE, R. L. The aesthetics of management storytelling. Manegement Learning, Thousand Oaks, v. 33 n. 3, p. 313-330, 2002.

SERIG, D. A conceptual structue of visual metaphor. Studies in Art Education, Ann Arbor, v. 47, n.3, p. 229-247, 2006.

WALLACE, A. R. Viagens pelos rios Amazonas e Negro. São Paulo: Edusp, 1979.

Artigo recebido em agosto de 2009 e aceito em maio de 2010. 